\title{
The Effect of Adult Attachment Style on Couples Relationship Satisfaction
}

\author{
Eyob Ayenew ${ }^{1 *}$
}

\section{ABSTRACT}

Background: There are different factors that contribute for the presence or absence of couple relationship satisfaction. However, very little is known about individual's characteristics that bring into their relationships which influence couple's relationship satisfaction. Adult attachment style is the one among these factors. Objective: The purpose of this study is to examine individual differences in relationship satisfaction using attachment theory as a framework. Methodology: A total of 306 (159 female and 147 male) participants were included from community sample. Three Kebeles in Yeka sub-city of Addis Ababa were selected randomly. Data were collected on relationship satisfaction and adult attachment. The constructs were measured by Relationship Assessment Scale (RAS, Hendrick, 1988) and Experience in Close Relationship Scale-Revised (ECR-R, Fraley et al., 2000). Pearson correlation and multiple regressions were run to check association and prediction among variables under study respectively. Result and Conclusion: The result confirmed that statistically significant correlation was found between/among most variables/constructs in the study. The standard regression revealed that both attachment dimensions (attachment anxiety and attachment avoidance) predicted relationship satisfaction. Participants who scored lower on both attachment dimensions reported higher relationship satisfaction. Implication: The research result has both theoretical and practical implications. Practically the study is beneficial for those policy makers and practitioners who work in the area of family (marriage) counseling and rights and well being of children.

Keywords: Adult Attachment Style; Relationship satisfaction, Couples

Close relationships are essential to health and well-being. The capacity to form intimate relationship with others is considered as an essential developmental task and a principal feature of effective personality development (Bowlby, 1988; Cassidy, 2001; Loubser, 2007). Adult intimate relationships are highly complex phenomena and span manifold level of analysis including; the person, his/her social, cultural and historical context of their interactions and the

\footnotetext{
${ }^{1}$ Assistant professor, Arba Minch University, Ethiopia

*Responding Author

(C) 2016 I E Ayenew; licensee IJIP. This is an Open Access Research distributed under the terms of the Creative Commons Attribution License (http://creativecommons.org/licenses/by/2.0), which permits unrestricted use, distribution, and reproduction in any Medium, provided the original work is properly cited.
} 
systemic interplay among those levels of analysis (Johnson, 2003; Reis, Clerk and Holmes, 2004). Consequently, there are different theories that attempted to explain intimate relationship. However, review of related literature on intimate relationships shows that attachment theory has became prominent theory to explain such relationship (Cassidy and Shaver, 1999; Loubser, 2007).

People strive to have successful intimate relationships, yet for centuries, the exact manner in which to accomplish this has remained an enigma. Although technological advances and gender egalitarianism made possible for researchers to study intimate relationships in greater detail, due to the complexity of the topic, research even in developed countries seems to scratch the surface (Plessis, 2006). In fact a great deal is known about the inner working of the couple relationship today than the previous times. Couple relationship is the emotional (eg. cohabitation) or emotional and legal (marriage) commitment between two opposite sex individuals to share emotional and physical intimacy, a variety of tasks and economic resources.

Marriage has long been an important social institution by forming family which occupies a central place in the lives of men, women, and children around the world. The fact that family is "a source of support, and sometimes an obstacle, to individual and collective achievements; a unit of economic production and consumption; an emotional haven that can sometimes be a source of emotional strain; and a vehicle for extending care giving and culture across the generations, for better and for worse (Laura, Lippman and Wilcox, 2013)".

Marriage in Ethiopia is one of the respected social phenomena as a rite of passage and forming well being that many people are going to engage. For instance, the result of the 2007 census (SCA, 2007) showed that 50 percent of the population was married from age of ten and only three percent divorced. Irrespective of the challenges and constraints facing now a days, couples are getting married to form life in an institution. However, it is important to remember that the simple presence of a spouse is not necessarily protective. There is a need to have strong emotional bond between couples so that marriage functions as an institution which results in reducing stress and maximizing satisfaction.

Bowlby in his attachment theory (1969) suggests that attachment is the deep emotional bond formed between infants and one or more adults; usually a parent or caregiver. This attachment provides a sense of security to children and allows them to explore their environment, returning to the adult during periods of distress. Development of this emotional bond or attachment involves parents providing love, nurturing, trust, safety and respect to their children and sensitively responding to their children's needs. The quality of the early parent-child relationship creates a framework of internalized expectations and beliefs about the self and the self in relation to others. The blueprint of such framework is long lasting and extended to adult romantic relationship (ISDP, 2004; Feeny, 2008; Simpson and Rholes, 2012). Therefore, attachment system affects the cognitive, emotional and behavioral responses in romantic relationship and 
expressed in an individual's internal working model of self and others (Collins and Read, 1994). The model of self and model of others can exist in conscious and unconscious level, which is relatively stable and influences later social and environmental interactions as well as personal developmental experiences.

Research has grown in the area of adult attachment and relationship satisfaction (Shi, 2003; Marchand, 2004; Simpson, Collins, Tran and Haydon, 2007; Rholes and Simpson, 2012). However, it is still scarce even nonexistent in Ethiopian case. The role of adult attachment style on relationship satisfaction have been overlooked. That is the basic reasons for the present researcher to focus on couple relationship satisfaction from attachment perspective.

\section{RESEARCH METHODS AND MATERIAL}

\section{Study Area}

The study area is Addis Ababa and was selected purposively. Addis Ababa represents a heterogeneous population in many social characteristics. The study included is heterosexual couples. Addis Ababa is the capital city of Ethiopia established in 1886. It is geographically located at the heart of the country. It accommodates about 35\% of the total urban population in Ethiopia. Addis Ababa City has a total population of 2,738,248 with a growth rate of 2.1 percent per annum (additional 57,503 people per year), where around 52\% of the populations composed of children and adolescents below age 25. From the total population, 48 percent are males and 52 percent are females (CSA, 2007). There is a seven year gap and recently the total population of Ethiopia assumed to reach to 90 million and the population of Addis Ababa also has increased. However, official documents are not yet revealed.

Addis Ababa City is divided into 10 Sub-cities; again the Sub-cities are divided in to 99 Kebeles. There is a disparity in Sub-city population distribution which shows uneven distribution. The whole population is urban dweller. The majority of the city population lives in Kolfe Keranyo (15.6\%) and Yeka (12.6\%), while Arada (7.7\%) and Akaki Kality Sub City (6.7\%) have the smallest share from the city's total population.

\section{Research Design and Population}

A non-experimental explanatory design was used to investigate the question of interest. The design is non-experimental because there is no manipulation of independent variables, which were investigated in the study. In this design, the levels or categories of the independent variables were already defined or classified so that the researcher has no opportunity to manipulate or randomly assign individuals to certain groups. It is explanatory since the objective of the study is to test hypotheses derived from a given theoretical orientation. Moreover, crosssectional method was used to collect data at a time to make comparisons across different categories of respondents. The target population of this study was adult heterosexual couples while the study population was adult heterosexual couples in Addis Ababa Administrative City. The study site overview and sampling techniques are presented hereafter. 


\section{Sample Size Determination and Sampling Procedure}

To determine the size of population having the attribute that is couple relationship (married) Central Statistics Authority (CSA, 2007), 50\% was used. Therefore, for single proportion population, to derive the sample size in relation to the total populations sizes the proportional distribution of the attributes taken in to consideration i.e. $50 \%$. Then at $95 \%$ confidence interval and $+/-5 \%$ significance level the sample size calculated became 384. Thus, 384 married (cohabited) from a total of 384 households were included in the study.

$$
\begin{aligned}
& \mathrm{n}=\left\{\mathrm{Z}^{2} \mathrm{x} \frac{p x q}{\mathrm{~d} 2}\right\} \\
& \text { Where: } \mathrm{n}=\text { sample size } \\
& \mathrm{z}=\text { Confidence interval (95\%) } \\
& \mathrm{p}=\text { Expected prevalence (as fraction of } 1 \text { ) } \\
& \mathrm{q}=1 \text { - } \mathrm{p} \text { (expected non-prevalence) } \\
& \mathrm{d}=\text { relative desired precision }
\end{aligned}
$$

Yeka sub city was taken purposely. Among the 10 Woredas in Yeka sub city, three were selected using simple random sampling method. To reach households which are the analysis unit of the study, systematic simple random sampling was used based on the sampling frame obtained from Keble household registration database.

\section{Data Collection Tools and Process}

The researcher used a demographic questionnaire and two structured questionnaires. The demographic questionnaire contains nine items that elicits personal information from each respondent. The structured questionnaire includes: Experiences in Close Relationships-Revised (ECR-R), to collect data on adult attachment experience and Rahim Organizational Conflict Inventory-II (ROCI-II), to make inventory on how respondents resolve conflicts with their partners.

\section{Experience in Close Relationships}

Fraley et al.'s (2000) ECR-R includes 36, 7-point Likert scale items in which 18 of them assess romantic attachment anxiety. Attachment anxiety measures the degree to which one fears being rejected, neglected or abandoned by romantic partners. The other 18 items assess romantic attachment avoidance which measures one's degree of discomfort with emotional closeness, openness and interdependence in romantic relationships. Items were rated on a scale ranging from 1 (strongly disagree) to 7 (strongly agree). ECR-R subscale scores for the two attachment dimensions of anxiety and avoidance are determined by calculating mean scores; lower scores on both dimensions reflect more secure attachment styles and higher scores on one or both suggest more insecure attachment styles. 


\section{Open-ended Questions}

To capture the personal opinion and to answer some research questions that could not be covered by the structured questionnaire or to supplement it, some open-ended items were prepared. These open-ended questions were focused on the factors that contribute to relationship conflict and the impact of conflict resolution styles on couple relationship satisfaction. The intention was to compensate the drawback of structured questionnaire by letting respondents to express their personal opinion, attitude and experience freely in their own words.

\section{Methods of Data Analysis}

Prior to conducting the analyses, the data collected were examined for accuracy of data entry, normality, missing values and co linearity. The data were found to have dependable data, normal distribution, no significant missing values and the scales and subscales which were considered as independent variables were not collinear. Person correlation was run to examine the relationship between adult attachment and relationship satisfaction. Multiple regressions were run with attachment anxiety and attachment avoidance as the independent variables and relationship as dependent variables.

\section{RESULTS}

Demographic Data (Categorical) $(n=306)$

\begin{tabular}{|c|c|c|}
\hline Demographic Variable & Frequency & Valid Percent \\
\hline 1. Sex & & 51.3 \\
\hline Female & 157 & 48.7 \\
\hline Male Total & 149 & $\mathbf{1 0 0}$ \\
\hline 2. Age & $\mathbf{3 0 6}$ & 6.9 \\
\hline 20- 25 years old & 21 & 71.9 \\
\hline 26-40 years old & 218 & 18.5 \\
\hline 41-60 years old & 56 & 2.6 \\
\hline$>60$ years old & 8 & $\mathbf{1 0 0}$ \\
\hline Total & 303 & 81.1 \\
\hline 3. Marital status & & 6.3 \\
\hline Married & 245 & 2.3 \\
\hline Cohabited & 19 & 9.9 \\
\hline Divorced & 7 & $\mathbf{1 0 0}$ \\
\hline Single & 30 & \\
\hline Total & $\mathbf{3 0 2}$ & 2.2 \\
\hline 4. Duration in relationship & & 39.2 \\
\hline < a year & 6 & 24.3 \\
\hline 1-5 years & 105 & 34.3 \\
\hline 6-10 years & 65 & $\mathbf{1 0 0}$ \\
\hline >10 years & 92 & $\mathbf{2 6 8}$ \\
\hline Total & & \\
\hline
\end{tabular}


The majority (71.9 \%) of the respondents were in the age category of 26 to 40 years old, which is relatively in early adulthood category of chronological age. The other 56 (18.5\%) fall in the age category of 41-60 years old which is congruent to the chronological age of middle adulthood. Therefore, most, $90.2 \%$ of the respondents were in early and middle adulthood chronological age. The majority, 245 (81.1\%) of the respondents reported that they are married, 30 (9.8\%) reported that they are single, $19(6.2 \%)$. Thirty nine percent of the respondents reported that they are in a relationship for one to five years, while 92 (34.2\%) of the respondents reported that they are in a relationship for more than 10 years.

Level of Education and Income (n=306)

\begin{tabular}{|c|c|c|}
\hline Variables & Frequency & Valid Percent \\
\hline 1. Education Level & & 3.0 \\
\hline Below high school & 9 & 21.9 \\
\hline High school complete & 66 & 35.9 \\
\hline Diploma/Certificate holders & 108 & 28.6 \\
\hline First degree holders & 86 & 10.6 \\
\hline Above first degree holders & 32 & 100 \\
\hline Total & 301 & \\
\hline 2. Monthly Income & & 3.7 \\
\hline No Income & 10 & 5.6 \\
\hline 500-1000 birr & 15 & 11.2 \\
\hline 1001-1500 birr & 30 & 7.4 \\
\hline 1501-2000 birr & 20 & 11.9 \\
\hline 2001-2500 birr & 32 & 60.2 \\
\hline Total & 162 & 100 \\
\hline
\end{tabular}

Approximately 36\% of the respondents were diploma/certificate holders, while $28.6 \%$ and 21.9 $\%$ were first degree holders and those who did finish high school (grade 10/12) respectively. Around 11\% respondents hold their second degree and above. This implies that more than 75.5\% of the respondents in the present study are trained in different fields with diploma and above. Moreover, $60.2 \%$ of the respondents earned more than 2500 Ethiopian birr per month while $11.9 \%$ of the respondents reported of getting 2001-2500 per month (Table 5). This implies that $72 \%$ of the research participants earned more than 2000 birr per month.

\section{Correlation between Demographic, Independent and Dependent Variables}

Pearson correlations were run between the demographic variables of age, education level, monthly income and relationship duration with the independent and dependent variables as follows. 
The Effect of Adult Attachment Style on Couples Relationship Satisfaction

Pearson Correlation between the Demographic Variables and the Independent and Dependent Variables

\begin{tabular}{|l|r|r|r|}
\hline & \multicolumn{1}{|c|}{ Aanx } & \multicolumn{1}{c|}{ Aavo } & \multicolumn{1}{c|}{ RS } \\
\hline Age & -.034 & .014 & -.010 \\
\hline Level of Education & $-.116^{*}$ & $-.142^{*}$ & -.017 \\
\hline Monthly Income & $-.301^{* *}$ & $-.268^{* *}$ & $.208^{* *}$ \\
\hline Relationship duration & -.089 & -.035 & .043 \\
\hline
\end{tabular}

Two-tailed significance: ${ }^{*} p<0.01 ;{ }^{* *} p<0.001$

Note: Aanx = Attachment anxiety, Aavo=Attachment avoidance, $\boldsymbol{R S}=$ Relationship Satisfaction,

In the above table, age and relationship duration were not statistically significant association with any of the independent and dependent variables included in the study. Respondents' education level has had statistically significant negative relationship with attachment style. Both Attachment anxiety and Attachment avoidance had inverse association with education level ( $\mathrm{r}=-$ $.116, \mathrm{p}<.01$ and $\mathrm{r}=.-142, \mathrm{p}<.01$ ) respectively. The important thing here is level of education has no statistically significant association with couple’s relationship satisfaction.

Monthly income had statistically significant correlation with attachment style. Attachment anxiety had statistically significant negative association with monthly income level, ( $\mathrm{r}=-.301$, $\mathrm{p}<.001$ ) and attachment avoidance had statistically significant negative association with monthly income $(\mathrm{r}=-.268, \mathrm{p}<.001)$. Unlike education level, income has statistically significant positive association with relationship satisfaction $(\mathrm{r}=.208, \mathrm{p}<.001)$. Therefore, the analysis shows that income has better association with the dependent and independent variables than any other demographic factors.

\section{Bivariate Correlation among Variables}

\begin{tabular}{|c|c|c|c|}
\hline Measures & $\mathbf{1}$ & $\mathbf{2}$ & $\mathbf{3}$ \\
\hline Aanx & 1 & & \\
\hline Aavo & $.55^{* *}$ & 1 & \\
\hline RAS & $-.35^{* *}$ & $-.43^{* *}$ & 1 \\
\hline
\end{tabular}

Correlations significant at the $p<0.01$ level are indicated by * and correlations significant at the $p<0.001$ level are indicated by $* *$

Note: Aanx = Attachment anxiety, Aavo=Attachment avoidance,, $\mathbf{R A S}=$ Relationship Satisfaction. 
Attachment anxiety had statistically significant negative relationship with relationship satisfaction $(\mathrm{r}=.35, \mathrm{p}<.001)$. Attachment avoidance had statistically significant negative association with relationship satisfaction $(\mathrm{r}=-.43, \mathrm{p}<.001)$. Therefore, the bivariate analysis shows that, inverse relationship was observed between adult attachment and relationship satisfaction.

Multiple Regression on Adult Attachment

\begin{tabular}{|l|c|c|c|c|c|}
\hline & Beta & t & P & F & R2 \\
\hline Regression & & & & & \\
DV: Relationship satisfaction & & & & & \\
IV: Anxiety & -.156 & -2.436 & 0.015 & 35.680 & $.203^{* *}$ \\
$\quad$ Avoidance & -.345 & -5.382 & 0.000 & & \\
\hline
\end{tabular}

Note: ${ }^{*} p<0.01,{ }^{* *} p<0.001$

The regression table shows the prediction power of adult attachment on relationship satisfaction. Therefore, both attachment anxiety and attachment avoidance contributed significantly to the prediction of relationship satisfaction with higher level of attachment anxiety and higher level of attachment avoidance associated with lower level of relationship satisfaction. The two dimensions in combination explained $20.3 \%$ of the total variance in relationship satisfaction.

\section{DISCUSSION}

Pearson correlations were run between demographic variables and the dependent and independent variables. Among other factors, level of education has statistically significant negative relationship with attachment anxiety and attachment avoidance. It implies that as the level of education get higher (degrees) peoples' attachment style became more of secure type. It is to mean that lower mean score in attachment anxiety and lower mean score in attachment avoidance show secure attachment style. The impact of education on attachment style therefore, is related with the score on both attachment dimensions. However, level of education and relationship satisfaction had negative association though it was weak (insignificant). This implies as education level increases, the satisfaction that couples derive from their relationship tends to fall. This seems something unexpected and the possible explanation may be individuals need and expectation became higher when one is educated more.

The result in the result chapter shows the association between monthly income and attachment style. Income had statistically significant negative association with adult attachment style. Low income was associated with high attachment anxiety and attachment avoidance or there was an inverse relationship between attachment style and level of income. This means, the level of income has the likelihood to increase the emotional bond between couples. The level of income has also statistically significant positive association with relationship satisfaction. This implies 
couples who earn better income have the likelihood to derive better relationship satisfaction or level of income has reasonable influence on couple's relationship satisfaction.

The analysis of the present study displayed statistically significant associations between adult attachment style and relationship satisfaction. Attachment anxiety and attachment avoidance had statistically significant negative relationship with relationship satisfaction. This implies that lower self-reported mean score of attachment anxiety and lower self-reported mean score of attachment avoidance resulted in higher relationship satisfaction. Higher self-reported mean score of attachment avoidance and higher self-reported mean score of attachment anxiety was associated with lower relationship satisfaction in couples. Therefore, the result of the present research regarding the relationship between adult attachment style and relationship satisfaction was in line with previous research reports (Mikulincer et al., 2002; Mikulincer and Shaver, 2007, Downing, 2008).

It was predicted that higher levels of attachment anxiety and attachment avoidance will be related to lower level relationship satisfaction. The present study confirmed this association. Attachment dynamics told us that partners with attachment avoidant and attachment anxious characteristics display their internal working models in different manners. But both constantly struggle with fear of losing their partners love and this force leads them to be overly avoidant and or overly anxious in their relationship.

Couples with an avoidant attachment style strived in every attempt to avoid working on disagreement, using the strategy of withdrawal, refusing to compromise or refusing to see others side when pursued within engagement (Shi, 2003). Consequently, hard feelings originating from unresolved issues and lack of essential problem solving communication will aggravate and lead to lowered relationship satisfaction. On the other hand, couples with anxious attachment style can suffer from lower confidence in their ability to keep couple relationship. When activated, anxiety interferes with the process of the important interactions. In both dimensions high scores leads to insecure attachment and dysfunctional conflict resolution styles and eventually results in low relationship satisfaction. For both groups, the feeling of insecurity leads to the engagement in conflict resolution styles that eventually reduce the satisfaction with the relationship (Simpson, Rholes and Phillips, 1996; Mikulincer and Shaver, 2003; Cann et al., 2008).

\section{CONCLUSIONS AND IMPLICATIONS}

Level of education had positive impact on adult attachment style. Couples who are more educated have the likelihood to control their emotion (less anxious) and confront problems (less avoidant) than those participants whose education level is low. Therefore, it can be concluded that although the level of education has the likelihood to contribute for secure attachment style in couple relationship, it did not guarantee for having relationship satisfaction. Income had significant impact in all adult attachment style and relationship satisfaction. The higher the income of the couples, the lower the score in their attachment anxiety and attachment avoidance. 
The higher the income the higher the relationship satisfaction couples derive from their romantic relationship. Therefore, it is possible to conclude that level of income is one of the factors that increase emotional bond and increase couples' relationship satisfaction.

The correlation result of the present research displayed statistically significant association among the variables (constructs) under study. Therefore, it is possible to conclude that the conceptual framework developed by the present researcher was more or less rectified. It was predicted that adult attachment style will be related to relationship satisfaction. The regression analysis shows that attachment style (anxiety and avoidant) predicts relationship satisfaction Therefore, it is possible to conclude that secure attachment style predicts relationship satisfaction.

The findings of the present study help to explain people's behavior for intervention. Some people have difficulties in starting and continuing adult intimate relationship and some others even seem to lack the wish or competence to become deeply involved with others. Because of the importance of adult attachment style to relationship satisfaction, it is helpful for marriage /couple/ therapists to address attachment issues and highlight how they are displayed in romantic relationships. For instance, in the present study, the two attachment dimensions contributed $20.3 \%$ of the variance in relationship satisfaction. Therefore, the characteristics of attachment anxiety and attachment avoidance displayed in the couple relationship deserve considerable attention. The counselor/therapist/social worker can work on changing negative models of the self and others by helping the couples to provide a secure base for each other.

\section{REFERENCES}

Bowlby, J. (1969). Attachment. New York: Basic Books.

Bowlby, J. (1988). A secure base. New York: Basic Books.

Cassidy, J. (2001). Truth, lies and intimacy: An attachment perspective. Attachment and Human Development, 3, 121-155.

Cassidy, J., and Shaver, P. (1999). (Eds.). Handbook of attachment: Theory, research, and clinical applications. New York: Guilford.

Collins, N. L. and Read, S. J. (1994). Cognitive representation of attachment to attachment: The structure and function of working models. Advances in personal relationships: Attachment process in adulthood, 5, 53-90.

CSA. (2007). Summary Report of the census of Ethiopia, Addis Ababa.

Downing, V. L. (2008). Attachment style, relationship satisfaction, gender role beliefs and the expression of authentic self in romantic relationships. Dissertation work, Maryland University.

Feeney, J. A. (2008). Adult romantic attachment: Developments in the study of couple relationships. In J. Cassidy and P. R. Shaver (Eds.). The handbook of attachment: Theory, research, and clinical applications (2nd ed., pp. 456-481). New York: Guilford Press. 
Fraley, R. C., Waller, N. G. and Brennan, K. A. (2000). An item response theory analysis of selfreport measures of adult attachment. Journal of Personality and Social Psychology, 78, 350-365.

Hendrick, S. S. (1988). A generic measure of relationship satisfaction. Journal of Marriage and the Family, 50, 93-98.

International Sexuality Description Project (ISDP) (2004). Patterns and universals of adult romantic attachment across 62 cultural regions. Journal of Cross-Cultural Psychology, 35, 367-401.

Johnson, S.M. (2003). Introduction to attachment: A therapist guide to primary relationships and theory renewal. Susan M. Johnson and Valerie E. Whiffen (Eds.). Attachment process in couple and family therapy (pp. 3-22). New York: Brunners.

Laura H., Lippman and Bradford W. (2013). World family map. Mapping family change and child well-being outcomes. An International Report from.al Report from

Loubser, J. (2007). Attachment theory and adult intimate relationships. Master thesis, Stellenbosch University.

Marchand, J. F. (2004). Husbands and wives marital quality: The role of adult attachment orientations, depressive symptoms and conflict resolution styless. Attachment and Human Development, 6, 99-112.

Mikulincer, M. and Shaver, P. R. (2003). The attachment behavioral system in adulthood: Activation, psychodynamics, and interpersonal processes. In M. P. Zanna (Ed.), Advances in experimental social psychology (Vol. 35). San Diego, CA: Academic Press.

Mikulincer, M. and Shaver, P. R. (2007). Attachment in adulthood: Structure, dynamics, and change. New York: Guilford.

Mikulincer, M., Florian, V., Cowan, P. A. and Cowan, C. P. (2002). Attachment security in couple relationships: A systemic model and its implications for family dynamics. Family Process, 41, 405-434.

Plessis, K. (2006). Attachment and conflict in close relationships: The association of attachment with , conflict beliefs, communication accuracy and relationship satisfaction. Dissertation work, Massey University: Albany.

Shi, L. (2003). The Association between adult attachment styles and conflict resolution in romantic relationships. American Journal of Family Therapy, 31, 143-157.

Simpson, A. and Rholes, W. (2012). Adult Attachment Orientations, Stress, and Romantic Relationships. Advances in Experimental Social Psychology, Vol. 45, 279-328.

Simpson, J. A., Collins, A. W., Tran, S. and Haydon, K. C. (2007). Attachment and the experience and expression of emotions in romantic relationships: A Developmental Perspective. Journal of Personality and Social Psychology, 92, (2) 355-367.

Simpson, J. A., Rholes, W. S. and Phillips, D. (1996). Conflict in close relationships: An attachment perspective. Journal of Personality and Social Psychology, 71, 899-914. 